\title{
One decade of imaging precipitation measurement by 2D-video-distrometer
}

\author{
M. Schönhuber ${ }^{1}$, G. Lammer ${ }^{1}$, and W. L. Randeu ${ }^{2}$ \\ ${ }^{1}$ Institute of Applied Systems Technology, Joanneum Research, Graz, Austria \\ ${ }^{2}$ Institute of Broadband Communications, Graz University of Technology, Graz, Austria
}

Received: 3 August 2006 - Revised: 12 February 2007 - Accepted: 21 February 2007 - Published: 26 April 2007

\begin{abstract}
The 2D-Video-Distrometer (2DVD) is a groundbased point-monitoring precipitation gauge. From each particle reaching the measuring area front and side contours as well as fall velocity and precise time stamp are recorded. In 1991 the 2DVD development has been started to clarify discrepancies found when comparing weather radar data analyses with literature models. Then being manufactured in a small scale series the first 2DVD delivery took place in 1996, 10 years back from now. An overview on present 2DVD features is given, and it is presented how the instrument was continuously improved in the past ten years. Scientific merits of 2DVD measurements are explained, including drop size readings without upper limit, drop shape and orientation angle information, contours of solid and melting particles, and an independent measurement of particles' fall velocity also in mixed phase events. Plans for a next generation instrument are described, by enhanced user-friendliness the unique data type shall be opened to a wider user community.
\end{abstract}

\section{Introduction}

Detailed knowledge on precipitation microstructure is one of the bases in various fields of sciences and applications, like terrestrial and satellite radio transmission, precipitation remote sensing, generally tropospheric wave propagation and atmospheric sciences. The development of an imaging 2D-Video-Distrometer began in 1991, when polarimetric weather radar data revealed unexpectedly high differential reflectivity values. The only way to investigate such measurements was recording rain microstructure characteristics under field conditions, including rain drop shapes. Video technology available on the market did offer sufficiently fast line scan cameras at reasonable price to allow such development.

Correspondence to: M. Schönhuber

(michael.schoenhuber@joanneum.at)

\section{2DVD features}

\subsection{Instrument setup}

The 2DVD measurement principle is based on two high speed line scan cameras, watching particles falling through a $25 \times 25 \mathrm{~cm}^{2}$ inlet of the housing. The crossed optical paths' common area is approximately $10 \times 10 \mathrm{~cm}^{2}$, constituting the virtual measurement area. The imaging grid resolution for raindrops is finer than $0.2 \mathrm{~mm}$, in both horizontal and vertical direction. The 2DVD presently consists of three main units, the Sensor Unit (SU), the Outdoor Electronics Unit (OEU) and the Indoor User Terminal (IUT). It is manufactured in a small scale series production, with first deliveries taking place in 1996 and 21 units being manufactured up to now. The original classic tall 2DVD version (cf. Fig. 1a) has been upgraded to the low-profile 2DVD version (cf. Fig. 1b), in reaction to publications (Nespor et al., 2000) indicating wind induced measurement errors caused by the shape of the classic tall Sensor Unit housing. Table 1 lists performance specifications for the low-profile version, being nearly identical to those of the earlier classic tall unit.

\subsection{Data type}

The imaging data give details on precipitation microstructure, including front and side contour for each particle, its fall velocity and precise time stamp, as well as bulk parameters like rain rate and size distributions. Such detailed particle information is recorded for each rain drop, snowflake, hailstone and melting particle. Figure 2a represents a screen dump of the data viewer main menu, showing a particle's front and side contour, a virtual top view of the measuring area, and indicating the five sub-menus with representations for rain rate, drop size distribution, fall velocity, an estimate for horizontal velocity of raindrops, and particles' height/width ratio. Measurement precision for individual particles is determined

Published by Copernicus GmbH on behalf of the European Geosciences Union. 

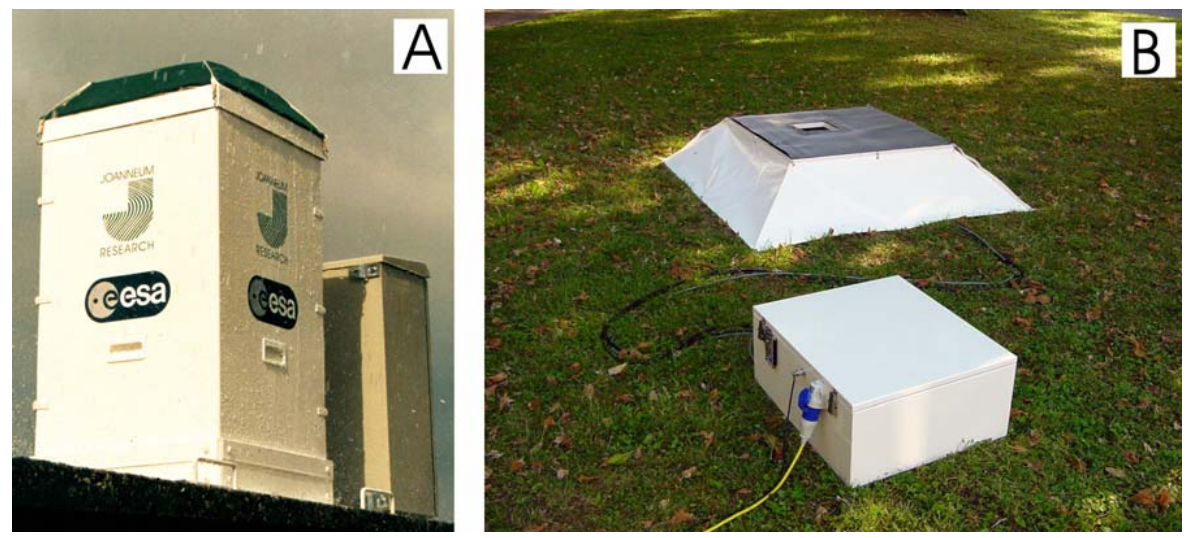

Fig. 1. Sensor Unit and Outdoor Electronics Unit of the classic tall (A) and low-profile 2DVD version (B).

Table 1. Low-profile 2DVD performance specifications.

\begin{tabular}{ll}
\hline resolution (horizontal) & $\begin{array}{l}\text { better than } 0.19 \mathrm{~mm} \\
\text { resolution (vertical) }\end{array}$ \\
$\begin{array}{l}\text { better than } 0.19 \mathrm{~mm} \text { for fall velocities less than } 10 \mathrm{~m} / \mathrm{s} \\
\text { better than } 4 \% \text { for velocities less than } 10 \mathrm{~m} / \mathrm{s}\end{array}$ \\
sampling area & $\begin{array}{l}\text { approximately } 100 \times 100 \mathrm{~mm}^{2} \\
\text { differences typically less than } 10 \% \\
\text { rain rate compared to tipping bucket } \\
\text { mains voltage }\end{array}$ \\
$\begin{array}{l}100-240 \mathrm{~V} \text { at } 50 / 60 \mathrm{~Hz} \\
\text { power consumption (SU, OEU, IUT) }\end{array}$ & approx. $500 \mathrm{~W}$
\end{tabular}

via the average values read from 100 calibration spheres. Results typically do not deviate more than 1 percent from the nominals, with diameter results being tested by spheres of $0.5 \mathrm{~mm}$ and bigger, and height/width ratio results being tested by spheres of $2 \mathrm{~mm}$ and bigger. Bulk parameters like rain rate compare to tipping bucket rain gauges typically with differences less than 10 percent. The algorithm to calculate the rain rate from individual rain drops' data is given in Schönhuber (1998) as Eq. 17, moreover comparisons of 2DVD vs. tipping bucket measured rain rates are given there in Fig. 63, Fig. 65 and Fig. 138. The line scan principle results in distortions whenever a particle's fall path is slanted, i.e. when its velocity vector has also a horizontal component. Then lines are shifted against each other. On the assumption that rain drops' views are axisymmetric, these distortions may be corrected and the true image recovered (Schönhuber, 1998). Figure $2 \mathrm{~b}$ shows a sample result, for the $6.6 \mathrm{~mm}$ drop of Fig. 2a indicating a canting angle of $4 \mathrm{deg}$ in its front view. Moreover for the height/width ratio two results are given, the first (left hand side) represents the ratio of longest vertical and horizontal dimensions, whereas the second number gives the ratio of axis of symmetry to its orthogonally longest dimension (cf. yellow and green line in Fig. 2b). Based on such data, predictions of transmission signal attenuation in rain and crosspolar discrimination are possible.

\subsection{Improvements during past decade}

First non-laboratory employments showed the potential of the 2DVD and its data type: in Lae/Papua New Guinea tropical rainfall was measured, quasi-mobile deployment in Colorado/US during a hail chase campaign yielded a database on continental type convective events and in Switzerland winterly precipitation in the Alpine mountain region was observed, focussing on melting layer studies. For the early 2DVD units a few critical performance issues were to be noted, which have been overcome by improvements during the past decade:

Alignment of optical components must be stable in spite of temperature variations, otherwise measurement precision and background illumination intensity is lost, resulting in shut down of the measurement process. Necessary improvements could be achieved by selection of construction material with suitable temperature coefficient.

Splashing onto optical surfaces results in constant objects to be recorded, in data overflow errors and measurement outages. As an early countermeasure redesign of the optical paths' slit structure included mirror heaters for rapid evaporation. With the low-profile 2DVD (cf. Fig. 1b) a sufficiently large distance between paths' slits and optical elements has been achieved, fully eliminating the splashing problem. 

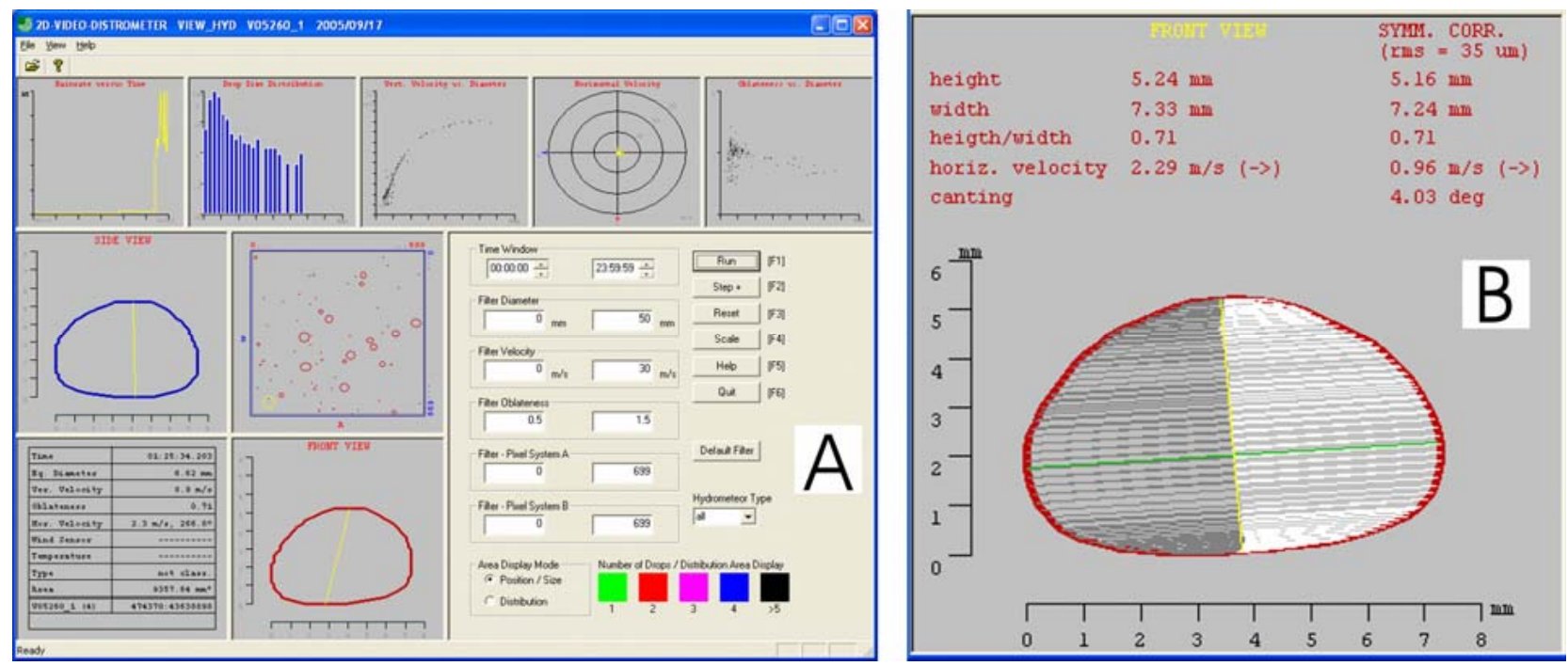

Fig. 2. 2DVD data viewer main menu (A) and drop contour analysis (B). Data recorded in Graz/Austria, 17 September 2005.

Turbulences around the classic tall instrument setup (cf. Fig. 1a) would distort measurement results in windy conditions, as was indicated by simulations (Nespor et al., 2000). Consequently a redesign resulted in the low-profile 2DVD version (cf. Fig. 1b), with the instrument's height decreased by a factor of 3. It is assumed that the flat and smooth shape of the low-profile 2DVD makes turbulence effects negligible.

Finer grid resolution of particles' contour data was achieved by employing faster cameras, increasing pixel frequency from $20 \mathrm{MHz}$ to $40 \mathrm{MHz}$.

Beyond the above four improvements individually mentioned, a big number of minor enhancements was applied in addition, in total resulting in a user-friendly and reliable instrument.

\section{Scientific merits}

\subsection{Validation by unique system performance analysis}

As to the authors' knowledge no other distrometer provides such detailed system performance and thus validation of results. Any potential calibration problems are immediately detected since particle contours would appear as distorted. In case of inhomogeneous filling of the measuring area for whatever reason, the virtual top view does indicate that.

\subsection{Measurement of big rain drops}

With the 2DVD there is practically no upper limit in measuring rain drop sizes. In natural rain the authors have found drops with equivolumetric sphere diameters of up to $7.9 \mathrm{~mm}$. Especially in mid-latitude convective events even for rather moderate rain rates drops in the size range of about
$7 \mathrm{~mm}$ were recorded. These observations answer the question of unexpectedly high weather radar differential reflectivity readings, mentioned in the Introduction.

\subsection{Measurement of drops' axis ratio and orientation an- gles}

From the 2DVD contour data rain drops' axis ratio values may be obtained and their orientation angles. Such knowledge is especially important when predicting crosstalk for frequency-reuse radio transmission, and for interpretation of polarimetric weather radar reflectivities. Figure $2 b$ shows an example of a drops' front view, with axis ratio and canting angle indicated.

\subsection{Measurement of solid and mixed phase particles}

Though knowledge on solid and mixed phase particles is of special importance for a thorough understanding of atmospheric situations and processes, relevant measurements are less available than rain recordings. The 2DVD is able to provide front and side contours also of melting and solid particles. Such information may be used for enhanced comparisons to weather radar reflectivities, measured close above the distrometer. With mixed phase events the portions of e.g. rain and hail may be separated in the 2DVD records and the wave propagation parameters separately be derived, summed up and then in total predicted for such precipitation type. Figure 3a presents front and side view of a snowflake, for example.

\subsection{Independent measurement of fall velocity}

2DVD fall velocity readings are independent, they are not based on any literature model or other assumption. Such 

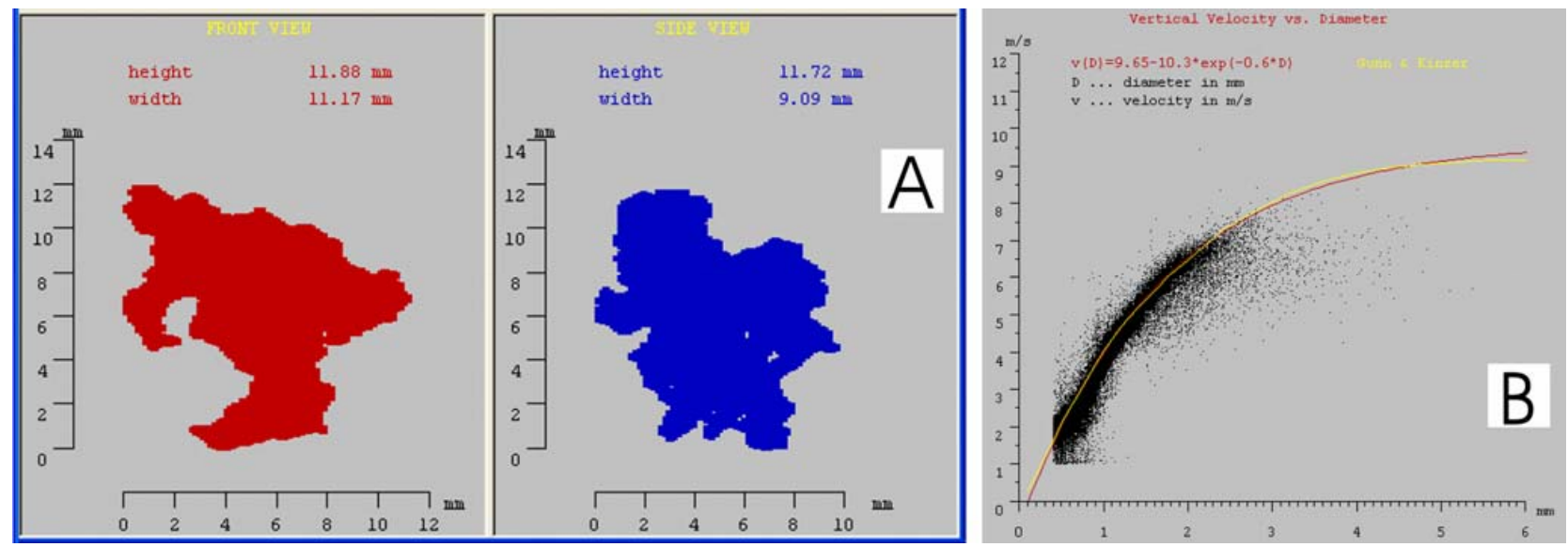

Fig. 3. Front and side view of snowflake (A), recorded in Graz/Austria, and fall velocity versus diameter diagram in a mixed phase event (B).

Table 2. Comparative summary of 2DVD version dependent key parameters (approximate values).

\begin{tabular}{lccccl}
\hline 2DVD version & $\begin{array}{c}\text { crate weight } \\
{[\mathrm{kgs}]}\end{array}$ & $\begin{array}{c}\text { crate volume } \\
{\left[\mathrm{m}^{3}\right]}\end{array}$ & $\begin{array}{c}\text { height of SU } \\
{[\mathrm{cm}]}\end{array}$ & $\begin{array}{c}\text { electr. power } \\
{[\mathrm{W}]}\end{array}$ & realignment \\
\hline classic tall & 265 & 2.3 & 105 & 500 & now and then \\
low-profile & 265 & 2.0 & 35 & 500 & rare \\
next gen. & 85 & 0.7 & 25 & 100 & never \\
\hline
\end{tabular}

information is of special value when analysing mixed phase events. Figure $3 b$ gives fall velocities versus diameter for a mixed phase event, clearly indicating that small particles already are fully melted to raindrops. Bigger particles still fall slower than raindrops of same size, indicating that they are made of a water-ice mixture. For comparison two rain drops' fall velocity literature models are indicated in Fig. 3b, the model by Atlas et al. (1973) drawn in red colour and the model by Gunn and Kinzer (1949) drawn in yellow colour. Moreover fall velocity information may be used for estimating the water equivalent of snowflakes and melting particles. Though the three dimensional microphysical structure is not fully represented by contour data, Schönhuber et al. (2000) have shown that a fair estimate for the water equivalent may be given, when adding the fall velocity information to the contour data analysis.

\subsection{Some recent data analyses by 2DVD users}

Up to now 21 2DVD units have been manufactured, they are used in various parts of the world, under various climatic conditions. The usefulness of data collected by the 2DVD has been demonstrated by a large number of publications, here only some recent ones shall be mentioned, all of them published within 2005: Attenuation and crosspolar discriminations were studied by Thurai et al. (2005) with a discussion on drop oscillations given by Thurai and Bringi (2005).
Intercomparisons regarding drop size distributions, rainfall rates and derived radar reflectivities, involving data from different instruments, were carried out by Bringi et al. (2005) and Kanofsky et al. (2005). A climatological analysis based on 2DVD data is presented by Schuur et al. (2005). Winter storm observations by radar and 2DVD are discussed by Ikeda et al. (2005).

\section{Plans for a Next Generation 2DVD Version}

A concept has been developed for ground breaking ease of maintenance and handling efforts, including a reduction of procurement costs. Finally a next generation 2DVD shall be available, offering the proven 2DVD data type at costs and operation conditions acceptable not only for research organizations and universities, but for a wider user community. This concept is based on two major principles, an in-plane configuration of the Sensor Unit's set up and the use of intelligent line scan cameras. Table 2 gives a comparative summary of 2DVD versions key parameters. Version independent parameters like imaging resolution are not included in Table 2 . 

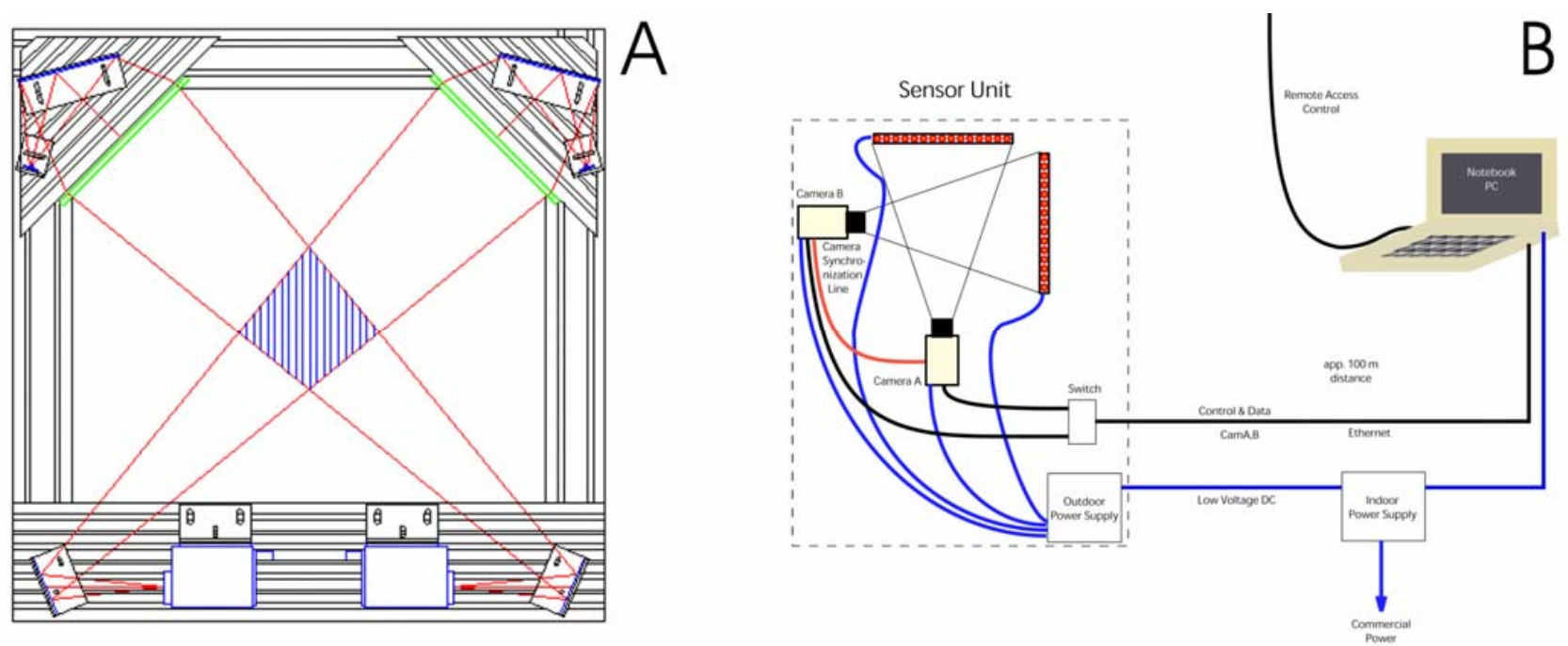

Fig. 4. 2DVD in-plane configuration scheme (A) and 2DVD block diagram using intelligent line scan cameras (B).

\subsection{DVD in-plane configuration}

Existing 2DVD units are built in a way that the optical paths are three-dimensionally arranged, this requires a voluminous sturdy construction to mount the optical elements onto. Alternatively a concept for a purely horizontal arrangement of the optical paths has been developed (cf. Fig. 4a), basic experiments have successfully confirmed its use. Onto a sturdy supporting structure of some $80 \times 80 \mathrm{~cm}^{2}$ the optical elements are mounted within a horizontal plane, in a way that the geometry for measurements finally results in the same data type and precision as provided by the existing bigger Sensor Units. The weight of the intended Sensor Unit thus may be decreased down to about $40 \mathrm{kgs}$, a reduction down to less than 50 percent. The compact design will allow omission of the alignment mechanics, instead the optical components will firmly be mounted during manufacture with no need for re-alignment by the user. Furthermore tests already gave confidence that for the in-plane configuration the presently used standard halogen bulbs may be replaced by LED illumination systems, increasing life time drastically, while simultaneously decreasing power consumption.

With the classic tall and also the low-profile 2DVD versions the distance of the optical slits to the rim of the housing is about $7 \mathrm{~cm}$, in case of significant wind speeds potentially hindering drops with slanted trajectories from reaching the measuring area. Though unwanted inhomogeneous filling of the measuring area is recognized in the virtual top view representation of the measuring area (cf. Sect. 3.1), with the new mechanical setup the distance of the optical slits to the rim of the housing shall be reduced and this unwanted effect then negligible.

\subsection{Intelligent line scan cameras}

The 2DVD is based on high speed line scan cameras, giving a data rate of $40 \mathrm{MB} / \mathrm{s}$ each. Such data rate still requires special handling, which presently is implemented by specific camera interface slotcards integrated into a Personal Computer located close to the Sensor Unit. This PC is housed within the Outdoor Electronics Unit. Recently intelligent line scan cameras are available on the market, offering sufficient embedded computing power for online data compression. Data may be compressed directly by the intelligent line scan camera applying a shading algorithm, then a threshold detection algorithm and finally by composing a run length code which further is sent to the Indoor User Terminal. A proof of this concept has successfully been carried out. Such setup allows to omit the Outdoor Electronics Unit and to reduce the whole setup to Sensor Unit plus Indoor User Terminal. A notebook PC can serve as indoor User Terminal (cf. Fig. 4b).

\section{Summary}

The 2DVD is an imaging precipitation gauge with a small scale series production of 21 units being manufactured in the recent ten years. The unique 2DVD data type supports tropospheric investigations in various ways, especially considering rain drops' axis ratios, snowfall analyses, and studies of the melting layer. Plans for a next generation 2DVD have been presented, by enhanced user-friendliness the unique data type shall be opened to a wider user community.

Edited by: S. C. Michaelides and E. Amitai

Reviewed by: anonymous referees 


\section{References}

Atlas, D., Shrivastava, R. C., and Sekhon, R. S.: Doppler radar characteristics of precipitation at vertical incidence, Rev. Geophys. Space Phys., 11, 1-35, 1973.

Bringi, V. N., Thurai, M., Nakagawa, K., Huang, G.-J., Kobayashi, T., Adachi, A., Hanado, H., and Sekizawa, S.: Rainfall estimation from C-band polarimetric radar in Okinawa, Japan : Comparisons with 2D-video disdrometer and $400 \mathrm{MHz}$ Wind Profiler, 32nd Conf. Radar Meteorol., Albuquerque, NM, USA, Amer. Meteorol. Soc., 24-29 October 2005.

Gunn, R. and Kinzer G. D.: The Terminal Velocity of Fall for Water Droplets in Stagnant Air, J. Meteorol., 6, 243-248, 1949.

Ikeda, K., Brandes, E. A., Zhang, G., and Rutledge, S. A.: Observations of Winter Storms with a 2-D Video Disdrometer and Polarimetric Radar, 32nd Conf. Radar Meteorol., Albuquerque, NM, USA, Amer. Meteorol. Soc., 24-29 October 2005.

Kanofsky, L. M., Chilson, P. B., Schuur, T. J., Zhang, G., and Brandes, E. A.: A comparative study of drop size distribution retrieval using two video disdrometers and a UHF wind profiling radar, 32nd Conf. Radar Meteorol., Albuquerque, NM, USA, Amer. Meteorol. Soc., 24-29 October 2005.
Nešpor, V., Krajewski, W. F., and Kruger, A.: Wind-Induced Error of Raindrop Size Distribution Measurement Using a TwoDimensional Video Disdrometer, J. Atmos. Oceanic Technol., 17, 11, 1483-1492, 2000.

Schönhuber, M.: About Interaction of Precipitation and Electromagnetic Waves, doctoral thesis, Institute of Communications and Wave Propagation, Technical University Graz, Austria, 181 p., 1998.

Schönhuber, M., Urban, H. E., Randeu W. L., and Poiares Baptista, J. P. V.: Field Measurements of Raindrop Orientation Angles, ESA SP-444 Proceedings, Millennium Conference on Antennas \& Propagation, Davos Switzerland, 9-14 April 2000.

Schuur, T. J., Ryzhkov, A. V., and Clabo, D. R.: Climatological analysis of DSDs in Oklahoma as revealed by 2D-video disdrometer and polarimetric WSR-88D radar, 32nd Conf. Radar Meteorol., Albuquerque, NM, USA, Amer. Meteorol. Soc., 24-29 October 2005.

Thurai, M. and Bringi, V. N.: Drop Axis Ratio from a 2D Video Disdrometer, J. Atmos. Oceanic Technol., 22, 966-978, 2005.

Thurai, M., Bringi, V. N., Huang, G. J., and Hanado, H.: Drop axis ratios and polarization dependence in rain from 2-Dimensional Video Disdrometer data, Third International Workshop of COST 280, Prague, 6-7 June 2005. 